\title{
Cyberbullying: argumentos, acciones y decisiones de acosadores y víctimas en escuelas secundarias y preparatorias de Colima, México
}

Cyberbullying. Arguments, Actions, and Decisions of Bullies and Victims in High Schools in Colima, Mexico

Cyberbullying. argumentos, ações e decisões de agressores e vítimas em escolas de ensino médio em Colima, México

\section{Antonio Gómez-Nashiki* iDorcid.org/0000-0001-9411-2422}

\section{Para citar este artículo}

Gómez-Nashiki, A. (2021). Cyberbullying. argumentos, acciones y decisiones de acosadores y víctimas en escuelas secundarias y preparatorias de Colima, México. Revista Colombiana de Educación, 1(83), 1-23. https://doi.org/10.17227/rce.num83-10681.

Fecha de recepción: 30/10/2019

\section{(C) $\underset{\mathrm{ar}}{(1)(9)}$}




\section{Resumen}

Palabras clave: violencia; bullying; comunicación

digital; escuela preparatoria
El artículo de investigación analiza el fenómeno del cyberbullying en seis escuelas secundarias y cuatro preparatorias públicas y privadas. Se realizaron entrevistas con acosadores, víctimas, estudiantes y docentes, además de la recuperación de fotos, imágenes, videos, mensajes escritos y de voz utilizados en los 25 casos en donde se presentó este tipo de acoso. Desde las bases de la teoría del poder, caracterizamos la relación asimétrica que prevalece entre los involucrados, las amenazas y contra amenazas que se registran, así como los distintos recursos que se movilizan (coacción, fuerza y violencia), con la finalidad de lograr la obediencia, lo que genera diversas consecuencias y daños sobre la víctima. Entre los principales hallazgos están los siguientes: a) acosadores: buscan el control total de las acciones de la víctima; la crueldad de algunos actos están relacionados con el poder que el agresor quiere que se le reconozca; un acosador ejerce violencia a más de una víctima; justifican sus acciones como parte de la cultura escolar que se da entre pares; b) víctimas: el miedo paraliza y anula su capacidad de respuesta, no denuncian por temor a sufrir agresiones; padecen un maltrato permanente que se traduce en sufrimiento, deterioro en su identidad y deseos de abandonar la escuela; las mujeres padecen más acoso de tipo sexual; c) los docentes no saben cómo proceder y demandan capacitación para su atención. El cyberbullying se manifiesta de diversas maneras y crece aceleradamente en las escuelas, genera subculturas delictivas que promueven individuos o grupos que legitiman sus acciones como una forma para reafirmar su poder.
Keywords: violence; bullying; digital communication; junior high schools; high schools

\footnotetext{
Palavras-chave: violência; bullying; comunicação digital; ensino médio
}

\section{Abstract}

The research article analyzes of cyberbullying in six secondary schools and four public and private high schools. Interviews were conducted with harassers, victims, students, and teachers, in addition to the recovery: photos, images, videos, written and voice messages used in the 25 cases where this type of harassment occurred. Starting from the bases of the theory of power, we characterize the asymmetric relationship that prevails between those involved, the threats and counter-threats that are registered, as well as the different resources that are mobilized (coercion, force and violence) to achieve obedience, generating various consequences and damages on the victim. Among the main findings show that: a) stalkers: seek completefull control of the victim's actions; the cruelty of some acts are related to the power that the aggressor wants to be recognized; a stalker uses violence against more than one victim; they justify their actions as part of the school culture that occurs between peers; b) victims: fear paralyzes them and nullifies their ability to respond, they do not report for fear of experiencing more aggressions; they suffer permanent abuse that translates into suffering, deterioration in their identity and desire to leave school; women experience more sexual harassment; c) teachers do not know how to proceed and demand training to attend to it. Cyberbullying manifests itself in various ways and grows rapidly in schools, generating criminal subcultures that promote individuals or groups that legitimize their actions as a way to establish their power.

\section{Resumo}

Este artigo de pesquisa analisa o fenômeno do cyberbullying em seis escolas secundárias e quatro escolas públicas e privadas em Colima, México. Foram realizadas entrevistas com assediadores, vítimas, estudantes e professores, além da recuperação de fotos, imagens, vídeos, mensagens escritas e de voz utilizadas nos 25 casos em que algum tipo de assédio ocorreu. Com base nas teorias do poder, caracterizamos a relação assimétrica que prevalece entre os envolvidos, as ameaças e as contra-ameaças registradas, bem como os diferentes recursos mobilizados (coerção, força e violência), a fim de alcançar a obediência, gerando várias conseqüências e danos à vítima. Entre os principais achados estão: a) Perseguidores: eles buscam o controle total das ações da vítima; a crueldade de alguns atos está relacionada ao poder que 0 agressor deseja ser reconhecido; um perseguidor usa a violência contra mais de uma vítima; eles justificam suas ações como parte da cultura escolar que ocorre entre pares. b) Vítimas: o medo as paralisa e anula sua capacidade de responder; elas não relatam o que aconteceu por medo de sofrer mais agressões; sofrem abusos permanentes que se traduzem em sofrimento, deterioração de sua identidade e desejo de deixar a escola; as mulheres sofrem mais assédio sexual. c) Os Professores não sabem como proceder e exigem treinamento para atendê-lo. Finalmente, o cyberbullying se manifesta de várias maneiras e cresce rapidamente nas escolas, gerando subculturas criminais que promovem indivíduos ou grupos que legitimam suas ações como forma de estabelecer seu poder. 


\section{Introducción}

\section{Bullying y cyberbullying}

El uso de las tecnologías de la información y comunicación (TIC) en el ámbito educativo es una forma novedosa de generar conocimientos y transmitir información, particularmente porque los niños, adolescentes y jóvenes son sus usuarios más asiduos y su empleo ha contribuido a la construcción de nuevos espacios de aprendizaje e interacción, sin embargo, también se han registrado eventos no deseados como el cyberbullying, cuya incidencia en los entornos escolares y extraescolares se ha incrementado en los últimos 20 años. Además, se ha expandido en diferentes partes del mundo, por lo que se ha convertido en un tema de investigación relevante (Gómez-Nashiki, 2020; Türker y Çakmak, 2019; Völlink et al., 2017; Waters et al., 2020).

El cyberbullying no solo es un problema de carácter psicológico, sino que también es un fenómeno socioeducativo, cuyas consecuencias van más allá de las aulas, con incidencia en el contexto personal, familiar y social de los implicados (Gómez-Nashiki, 2020). Se considera un tipo de violencia con características particulares (Rosa et al., 2017; Slattery et al., 2019), se define como

un acto agresivo e intencional, utilizando formas electrónicas de contacto, desarrollado por un individuo o grupo de personas de forma repetida y mantenida en el tiempo sobre una víctima que no puede defenderse fácilmente por sí misma. (Smith et al., 2008, p. 377)

Algunos autores (Adorjan y Ricciardelli, 2019) coinciden en señalar la posibilidad de tipificarlo como un delito por la intencionalidad del daño, así como las secuelas -en ocasiones permanentes- que producen en el desarrollo socioemocional de una persona.

De acuerdo con la literatura especializada (Choon et al. 2020; Miller, 2017; Scheerder et al., 2019), las características más significativas de este tipo de acoso son a) el acecho constante que se identifica en acciones molestas e intimidantes no solicitadas. Los dispositivos electrónicos pueden programarse automáticamente por lapsos de tiempo prolongados; b) no hay barrera espacial que lo límite; c) la imagen del agresor es difusa, porque el acoso se puede llevar a cabo de manera anónima, a través de la creación de perfiles falsos que dificultan la identificación y rastreo; d) es fácil vulnerar la identidad de la víctima, suplantarla para llevar a cabo diversas comunicaciones o el robo de identidad, dinero o propiedad y afectaciones a su intimidad; e) puede ejercerse de manera individual o colectiva (acosadores severos, ocasionales e implicados); f) es frecuente el uso de un lenguaje intimidatorio y el uso de expresiones discriminatorias y con reiteradas amenazas a la integridad del individuo, familia y bienes; g) el alcance de la agresión puede extenderse a distintos públicos, e ir más allá de los ámbitos escolares en donde se originó; h) la emisión de mensajes, imágenes y videos con tono lascivo se convierten en estigmas permanentes que no pueden ser borrados fácilmente de la red y cuya difusión es inmediata y masiva; i) difundir, comunicar y compartir datos o información sin consentimiento de la víctima sobre información privada que afecte su persona; j) "los testigos", al reenviar los textos e imágenes ejercen una doble violencia, pues adoptan un papel activo de apoyo al acosador difundiendo las ofensas, compartiendo el rol de agresores; k) son limitados los recursos disponibles para que la víctima pueda denunciar, 
aunado a omisiones por parte de actores con poder regulatorio; I) los efectos psicológicos sobre la víctimas son graves, pues dan origen a sentimientos de inseguridad, persecución, miedo, e incluso, generar ideas suicidas en las víctimas; m) la legislación educativa para afrontar el cyberbullying es escasa y poco precisa.

\section{La producción académica}

La publicación de trabajos sobre el tema de la violencia escolar se ha multiplicado de manera notable a partir de la década de los 80, sin embargo, un tipo de violencia en específico: el bullying, acaparó la atención de diversos investigadores alrededor del mundo y la producción académica ha sido por demás elevada (Herrera-López et al., 2018; Purdy, 2019; Torres et al., 2019; Yudes-Gómez et al., 2018). El mismo énfasis se ha presentado con el cyberbullying, que en aproximadamente dos décadas ha generado que la producción sea constante; en este caso, el fenómeno presenta algunas particularidades que son importantes tomar en cuenta para llevar a cabo su análisis, entre las que podemos señalar las siguientes: es difícil estimar con certeza su magnitud, así como la velocidad con que se propaga, debido al anonimato con que se realiza, lo que dificulta contar con datos precisos (Baldry et al., 2016; Shiakou y Piki, 2018); en la literatura no hay un consenso acerca de cómo definirlo, se mencionan conceptos como ciberviolencia, ciberagresión, ciberpersecución, ciberacoso, victimización en línea, ciberhostigamiento, entre otras (Völlink et al., 2017; Seetharaman y Bhatt, 2019).

En cuanto a la forma en que se ha estudiado el cyberbullying, se han considerado las siguientes variables: constatación de su presencia en las aulas, a partir de la opinión de los estudiantes -con el uso de encuestas- (Coelho y Sousa, 2018; Herrera-López et al., 2017; Zhen y Yuanyuan, 2019), rasgos que prevalecen en los acosadores y víctimas (Herrera-López et al., 2018); daños inmediatos y repercusiones a largo plazo que manifiestan los estudiantes (Hamal et al., 2019); medios que se emplean: páginas web, chats, foros y mensajes instantáneos (Aftab, 2006); el uso de diferentes dispositivos: teléfonos móviles, computadoras y tablets (Domínguez-Alonso et al., 2017); los tipos de agresiones más frecuentes (Adorjan y Ricciardelli, 2019); riesgos y daños al que están expuestos los niños y jóvenes, tanto en las aulas como fuera de la escuela (Lehman, 2020); la edad de los protagonistas (Paez, 2018; Redondo-Pacheco et al., 2018); el género, como factor para explicar el tipo de acoso entre agresores y víctimas (Donoso-Vázquez et al., 2017; Warwick y Purdy, 2019); las características del agresor y la víctima: motivaciones y percepciones (Campbell et al., 2018), así como los tipos de daño psicológico que sufren las víctimas (Miller, 2017); efectos socioemocionales que tiene sobre los sujetos: persecución, paranoia, angustia, miedo, soledad (Baeza et al., 2010; Wagner, 2019) y conductas autodestructivas registradas por las víctimas: depresión e ideas suicidas (Barzilay, 2017; Hinduja y Patchin, 2018).

El balance muestra que es importante promover el desarrollo de investigaciones que a) desde el enfoque cualitativo analicen las percepciones, opiniones y argumentos que manifiestan las víctimas, acosadores, testigos, directores, docentes y padres de familia (Cortés-Pascual et al., 2020); b) lleven a cabo análisis comparativos, tanto a nivel nacional como internacional ${ }^{1}$ (Graham y Wood, 2017); c) propongan alternativas de solución accesibles y contextualizadas para las escuelas en los diferentes niveles (Al-Rahmi et al., 2020); d) desarrollen propuestas de evaluación, tanto cuantitativa como cualitativamente, para las

\footnotetext{
${ }^{1}$ Por ejemplo: Threat Assessment of Bullying Behaviours Among Youngsters (TABBY).
} 
diversas políticas, programas y estrategias implementadas para valorar su eficacia (Baldry et al., 2018); e) impulsen estudios que desde una perspectiva legal apoyen en la solución de los conflictos que se registran en las diferentes instituciones educativas (Wagner, 2019). Por último, es importante mencionar que son escasos los trabajos que, además de las entrevistas a los protagonistas, incluyan videos, fotos, correos electrónicos, mensajes de voz, mensajes de texto como parte de la evidencia empírica.

\section{Abordajes teóricos sobre el cyberbullying}

Algunos postulados teóricos se han utilizado para explicar la presencia del cyberbullying (Espelague et al., 2018), destacan las siguientes: a) la teoría cognitiva social de Bandura (1987) establece que tanto el bullying como el cyberbullying son una muestra del comportamiento agresivo aprendido en el contexto social: escuela, casa y principalmente de los medios de comunicación, así como la exposición a determinados contenidos; b) teoría de la actividad rutinaria, propuesta por Cohen y Felson (1979), en donde la accesibilidad a la tecnología por parte de los jóvenes, en un contexto sin tutela y supervisión efectiva de padres y maestros, favorece la creación de espacios para que un ciberagresor se desarrolle y actúe; c) la teoría de la tensión general, de acuerdo con Agnew, los jóvenes que experimentan tensión pueden liberar su frustración hacia otros, por medio de abusos verbales o insultos, a través del ciberespacio y sin control parental (2001); d) teoría del aprendizaje social de Akers (1998), establece la alta probabilidad que existe de que un individuo aprenda y cometa un crimen si se asocia con pares que lleven a cabo estos actos, como en el cyberbullying, y e) teoría de la acción situacional de Wikström (2014), enfocada en explicar tanto las acciones que siguen los acosadores como la actitud que presentan las víctimas en un conflicto de cyberbullying, a partir de dos consideraciones: los aspectos sociales y psicológicos y el contexto en que se encuentran los individuos involucrados.

Desde nuestra perspectiva, es la teoría del poder (Escobar, 1988; Arendt, 1970; Weber, 1992; Priya y Eshan, 2019) la que permite identificar cómo, en el contexto de las diversas relaciones sociales, "se verifica la presencia de un sujeto activo que instrumenta la voluntad de otro pasivo, en virtud del cual el primero manda y el segundo obedece" (Escobar, 1988, p. 30).

A partir de esta concepción, destacamos la relación asimétrica que prevalece, la noción de mandato, y las acciones de amenaza y contraamenaza que se registran en un espacio de conflicto (Menge, 2019), así como los distintos recursos de poder que se movilizan (coacción, fuerza, violencia) con la finalidad de lograr la obediencia, lo que genera diversas consecuencias y daños sobre la víctima.

\section{Metodología}

El objetivo general de este artículo fue analizar el fenómeno del cyberbullying en seis escuelas secundarias (con estudiantes de entre 12 y 15 años) y cuatro preparatorias (con estudiantes de entre 16 y 19 años), tanto públicas como privadas del Estado de Colima. Los objetivos específicos fueron los siguientes: a) caracterizar las razones y acciones utilizadas por los alumnos considerados acosadores y víctimas, así como decisiones adoptadas y consecuencias de sus conductas y b) conocer la opinión de directivos, docentes, padres de familia y estudiantes sobre el fenómeno del cyberbullying. 


\section{Preguntas de investigación}

¿Para los acosadores y víctimas, ¿qué implicaciones tiene el cyberbullying en la constitución de su identidad social y cultural?, ¿qué argumentos manifiestan los acosadores y víctimas para justificar sus acciones?, ¿qué información tienen docentes y padres de familia de este fenómeno?, ¿qué estrategias institucionales se han implementado para atenderlo?

\section{Muestra}

Se trata de una muestra intencional y no representativa estadísticamente (Miles y Huberman, 1994). Se utilizaron herramientas etnográficas: la entrevista, el diario de campo y la observación (Hammersley y Atkinson, 1994; Bertely, 2000); con un corte cualitativointerpretativo; la explicación se da por parte de los sujetos, el material empírico y los referentes teóricos, pero también por las consideraciones personales y el proceso de autocomprensión logrado a partir de la interacción con los sujetos y sus contextos, aspectos que permitieron narrar, interpretar y producir un texto.

Conseguir las evidencias implicó realizar una gran cantidad de entrevistas y, como ocurre con el bullying tradicional, no todas las acciones cumplían con el criterio de reiteración sobre una víctima. Adicionalmente, tener acceso a los mensajes, imágenes, fotos y videos, tanto de los agresores como de las víctimas, requirió del permiso de los involucrados y, en algunos casos, de las autoridades educativas y padres.

Los casos que sirvieron de base para este artículo fueron proporcionados directamente por los acosadores y su círculo más cercano, en el caso de las víctimas, fue a través de docentes, padres de familia, directores y compañeros de clase, quienes por distintas razones denunciaron e hicieron públicos estos acontecimientos. Se identificaron a 25 sujetos involucrados, 12 casos en el nivel secundaria y 13 en preparatoria. Las variables que se consideraron fueron sexo, edad, nivel educativo, tipo de escuela, perfil de los acosadores y las víctimas (tabla 1 ).

Tabla 1.

Sujetos, municipios y entrevistas realizadas

\begin{tabular}{|c|c|c|c|c|}
\hline & Colima & Manzanillo & Tecomán & $\begin{array}{c}\text { Villa de } \\
\text { Álvarez }\end{array}$ \\
\hline Docentes & 7 & 2 & 4 & 6 \\
\hline Acosadores & 5 & 1 & 2 & 4 \\
\hline Víctimas & 6 & 1 & 1 & 5 \\
\hline Padres de familia & 5 & 3 & 2 & 8 \\
\hline Directores & 1 & 0 & 0 & 2 \\
\hline Total & 24 & 7 & 9 & 25 \\
\hline
\end{tabular}

Fuente: elaboración propia.

La investigación duró un año y finalizó en el mes de julio del 2019. Las entrevistas y observaciones se desarrollaron en un lapso de siete meses; por las características del tema se plantearon como un diálogo con una parte semiestructurada, a partir de un guion establecido. El protocolo de la entrevista consistió en explicar los objetivos del proyecto y solicitar la autorización para grabar los testimonios y publicarlos en este artículo. Se les informó a los participantes que sus nombres no aparecerían en el trabajo, ni la dirección de sus correos o cuentas de las diferentes redes sociales, pues lo que importaba era el hecho y 
la narrativa de los acontecimientos. En todos los casos, los participantes aceptaron sin restricción alguna y estuvieron de acuerdo.

\section{Proceso de análisis}

Las entrevistas se transcribieron y analizaron de la siguiente manera: para cada una de ellas se diseñó un mapa conceptual (figura 1) con la finalidad de identificar los argumentos expresados por las víctimas y acosadores, así como las ideas y conceptos que expresaban, identificadas con diferentes colores para facilitar su sistematización. Se diseñó una matriz que incluyó diferentes puntos de vista de los sujetos de estudio para poder establecer la relación que guardaban con las precategorías y categorías identificadas (Hammersley y Atkinson, 1994, p. 197).

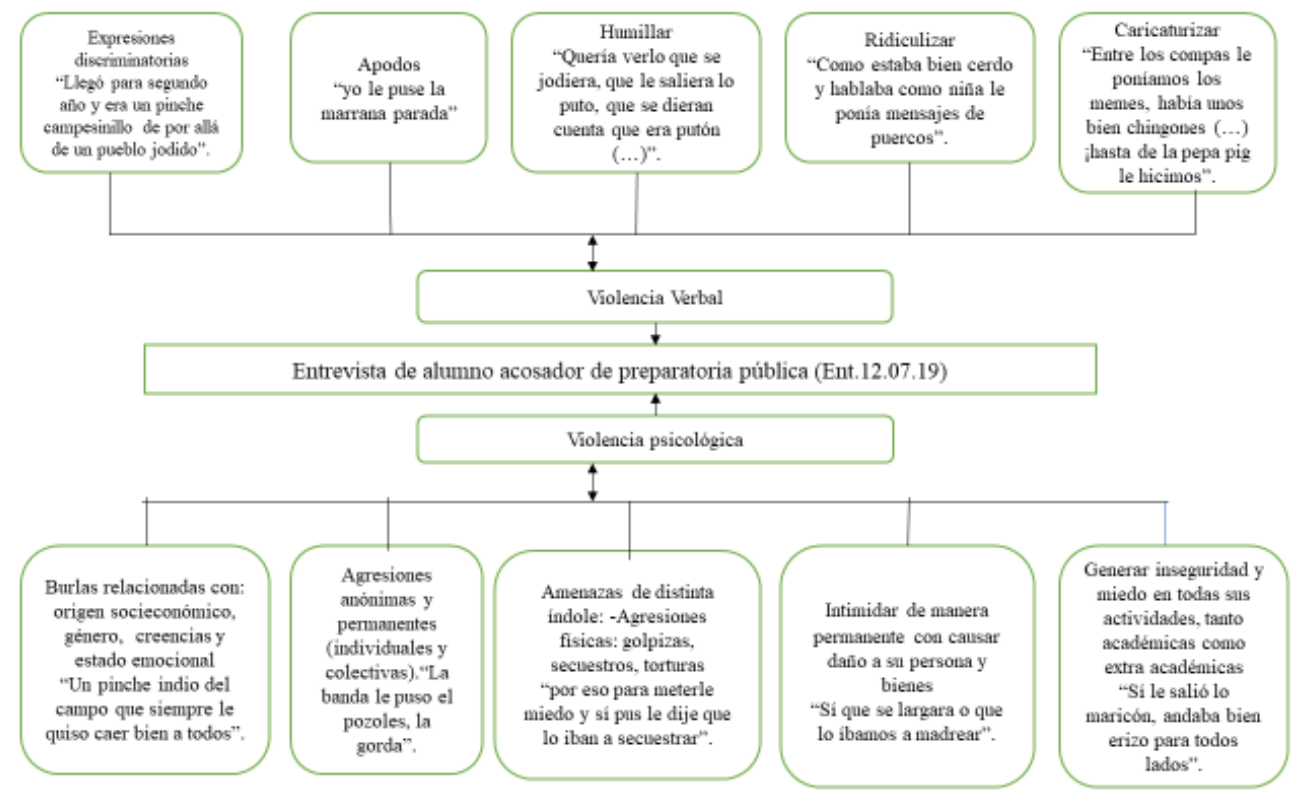

Figura 1. Mapa conceptual de una entrevista, a partir de las categorías de violencia verbal y psicológica. Fuente: elaboración propia.

El material empírico reunido contiene 43 mensajes de texto, 7 de voz, 35 imágenes de memes, 15 fotos. La mayoría muestra los genitales u otras partes íntimas y 17 videos de peleas, golpizas o de situaciones en las que se ridiculiza a la víctima, además de otros temas como personas torturadas, secuestradas, suicidios, etcétera. Se transcribieron los mensajes de texto y de voz, en el caso de las imágenes, memes, fotos y videos; se realizó una ficha de análisis de cada uno (Miles y Huberman, 1994), que incluyó la fecha de elaboración, autor o emisor, destinatario y descripción detallada del material: tema principal, protagonistas involucrados y tipo de violencia(s) que mostraban, con el propósito de contrastarlas con la matriz de precategorías elaborada para las entrevistas. El siguiente paso fue la triangulación, que consistió entre la comparación de los relatos de los diferentes participantes, el material empírico recuperado y los conceptos revisados en la teoría vinculados al objeto de investigación. De esta manera, se obtuvieron las categorías definitivas que se desarrollaron a 
lo largo de la investigación (Hammersley y Atkinson, 1994, p. 216).

\section{Cuadro 1.}

Categorías y precategorías utilizadas en la investigación

Poder

- Un sujeto activo que instrumenta la voluntad de otro pasivo, en virtud del cual el primero manda y el segundo obedece.

- Relación asimétrica que prevalece, imposición de mandato.

- Acciones de amenaza y contraamenaza que se registran en un espacio de conflicto, así como los distintos recursos de poder que se movilizan.

- Actos agresivos e intencionales que utilizan formas electrónicas de contacto, desarrollado por un individuo o grupo de personas de forma repetida y mantenida en el tiempo.

Violencia psicológica

- Agresiones anónimas y permanentes (individuales y colectivas).

- Burlas relacionadas con origen socieconómico, género, creencias y estado emocional.

Amenazas de distinta índole:

- Agresiones físicas: golpizas, secuestros, torturas.

- De connotación sexual: envío de fotos de partes íntimas, desnudos o de actos sexuales (sexting); difusión de imágenes sin consentimiento de la víctima (sextorsion); publicación en redes sociales de videos o fotografías sexuales de exparejas como forma de revancha (sexovenganza).

- Difusión de mensajes falsos, atribuidos a la víctima.

- En contra de su vida y de sus familiares.

- Chantajear con difundir información privada.

- Intimidar de manera permanente con causar daño a su persona y bienes.

- Controlar su interacción social: pares y amistades.

- Generar inseguridad y miedo en todas sus actividades, tanto académicas como extraacadémicas.

Violencia verbal

- Expresiones discriminatorias

- Apodos

- Humillar

- Ridiculizar

- Caricaturizar

- Alburear 


\section{Cultural institucional}

- Arena de disputa y conflicto.

- Códigos y legalidades subterráneas entre los jóvenes que difícilmente logran traducción en el mundo adulto.

- Trama de símbolos y rituales que confiere a la violencia un lugar privilegiado, la idealiza y refuerza su perpetuación.

- Rompimiento de pactos y contratos que garantizan la estabilidad, seguridad y confianza del sujeto: sufrimiento.

- Acciones violentas que se legitiman, bajo el discurso de hechos comunes y triviales.

- Legislación y normas poco precisas para atender el cyberbullying.

- Omisión por parte de responsables institucionales con poder regulatorio (docentes y director).

Identidad

- Desprestigio social.

- Estigmatización.

- Creación de atributos negativos sobre la víctima y familiares.

- Segregación.

- Marginación.

- Exclusión (actividades escolares y recreativas).

- Discriminación.

- Robo y suplantación de identidad.

- Anonimato, libertad para ejercer violencia.

- Creación de múltiples identidades: Yo on line.

- La violencia como referente en la construcción de la identidad del acosador y simpatizantes.

Fuente: elaboración propia.

Nota: Durante las agresiones sobre una víctima se pueden presentar de manera simultánea, y en distinto orden, varios tipos de violencia; sin embargo, para fines analíticos se presenta de esta manera.

Se utilizó la descripción densa (Geertz, 2006) como una herramienta metodológica para dar cuenta de lo acontecido en profundidad en una institución, así como de los sujetos que la integran, lo que obligó a revisar múltiples episodios, relatos y evidencias que van más allá de una descripción lineal, porque lo que se privilegiaron los distintos elementos que rodean a los sujetos involucrados en el relato. Narrar, en este sentido, sirvió para organizar los diversos argumentos, interacciones, juicios y evidencias, con el propósito de someterlos al análisis de una manera legible y razonada (Ricoeur, 2007). 


\section{Resultados}

\section{Ejercicio del poder}

El poder es un elemento que se encuentra presente en casi todas las relaciones sociales asimétricas y en donde prevalece la superioridad de uno de los participantes, identificado como acosador, que instrumenta la voluntad de otro pasivo (Menge, 2019), léase víctima, en virtud del cual el primero manda y el segundo obedece, "el poder es el ejercicio de la dominación y del sometimiento" (Foucault, 1988, p. 78).

Se trata de una situación de violencia que utiliza la fuerza cuando los sujetos entran en conflicto (Boyle, 2020). Por esta razón, se ven obligados a ejercitar, recíprocamente, las amenazas y contraamenazas respectivas (Escobar, 1988).

El cyberbullying es un recurso de poder que utilizan distintos sujetos ante situaciones específicas, en el caso de los alumnos, forma parte de una fuerza abierta u oculta, con el fin de obtener de un individuo o de un grupo algo que no quiere consentir libremente. De acuerdo con los relatos de los agresores y las evidencias obtenidas, las amenazas permanentes están encaminadas a disminuir la capacidad de respuesta de la víctima, lo que inicia un proceso de depredación, que es un acto que pretende apropiarse de la vida de otro (Hirigoyen, 1999), a través de un mecanismo de estricta vigilancia (Foucault, 1988) y de la generación de temor constante, que reduce los umbrales de resistencia frente a una amenaza. La otra vertiente se encuentra en la suplantación de la persona, para hacerla quedar mal en sus opiniones y acciones, con el propósito de desprestigiarla socialmente.

La intensidad de la agresión, así como la crueldad de algunos actos, están relacionados con el poder que el agresor quiere manifestar (Olweus, 2003), es decir, su capacidad de hacer daño a la víctima está en función del poder que busca exhibir y sea reconocido, por ejemplo, este testimonio:

Alumno, preparatoria, privada: "Si vieras como lloraba ya al final el putito ese, parecía vieja neta, ya ni aguantaba nada, yo [...], ino le paré!, ime pararon!, me lo chingué, ya se veía bien zombie (risas). (Ent.13.03.19)"

De acuerdo con Wagner (2019), se trata de una acción dinámica violenta que se va afinando en función de su implementación sobre la víctima. En los casos identificados, se observan una serie de estrategias encaminadas a causar miedo, terror, ansiedad, ira y angustia en las víctimas seleccionadas; un ejercicio de la violencia en donde se experimentan y ensayan las diferentes acciones y reacciones cotidianas de los sujetos para incrementar y apuntalar la agresión, pues los mensajes giran en torno a provocar malestar, daño psicológico y físico:

Alumna, preparatoria pública: "Vuelbe a subir uuuuuna pinche foto, uuuna con mi ex perra y ite parto tu pinche madre!". (Mensaje de texto, 08.04.19)

El proceso de acoso que se pone en marcha parte de un cuidadoso análisis que establece el agresor para recuperar distintos tipos de información de la víctima como gustos, intereses, problemas, situación familiar, escolar, entre otros aspectos, con el propósito de elaborar un amplio perfil que le permite focalizar la violencia en lugares clave y someterlo mediante múltiples amenazas para que obedezca (Tosuntaş et al., 2018). Las amenazas son el mecanismo que respalda al mandato que emite el sujeto activo, es decir, apropiarse de los 
distintos ámbitos que lo rodean, "con el objetivo de que el individuo se amilane y viva temeroso de quienes lo juzgan, sin intentar ningún tipo de reacción" (Rodríguez, 2002, p. 87).

Por ejemplo, aislar a la víctima del ambiente escolar y cerrarle los espacios de comunicación en las diferentes redes sociales como este testimonio:

Alumna: "Le dije a todos que la bloquearan del whatts y del face por pinche zorra culera [...] y isí!, iun chingo me hicieron caso! (Risas)". (Ent.19.10.18)

La narrativa de los acosadores se centra, por una parte, en interpretar las acciones de la víctima como si estuvieran dirigidas estrictamente a él y, por esta razón, le niega "al otro" un lugar en el mismo espacio social, que es una justificación anticipada para legitimar los distintos tipos de violencia a utilizar, por ejemplo, las amenazas explícitas a la integridad física de la víctima:

Alumno, preparatoria pública: "T vamos a koger entre todos pinche puta, cuídate". (Mensaje de texto, 09.05.19)

Alumno, preparatoria pública: "¿Sabes lo que es el secuestro culero?". (Mensaje de texto, 18.10.18)

Hasta las más extremas como la amenaza de muerte que una de las víctimas narró:

Alumna de preparatoria privada, 17 años: "Me sentía muy sola [...], me amenazaron de muerte ¿tú crees?, fue mi exnovio, quería que regresáramos [...], me decía que iba a publicar fotos de nosotros cuando estábamos juntos, que si no volvíamos me iba a matar [...], todavía me da miedo ¿no? [...], mi hermana fue la que le dijo a mis papás $[. .$.$] , de repente llegan groserías y$ fotos horribles todavía por el Whatts". (Ent.05.12.19)

Los mecanismos de acecho que se ponen en marcha buscan, por una parte, llamar la atención de manera inesperada, pero, por otra, que la víctima racionalice lo que le puede ocurrir, que son las bases del miedo, de acuerdo con Delumeau: "El miedo (individual) es una emoción-choque frecuentemente precedida de sorpresa, provocada por la toma de conciencia de un peligro, presente y agobiante, que según creemos amenaza nuestra conservación" (2012, p. 28).

Por ello, la amenaza y los peligros que representa para la víctima generan en el corto plazo la producción de cambios conductuales y modificaciones en su estructura cognitiva y empiezan a respetar de manera inconsciente las órdenes del acosador, mostrando nula capacidad de criticar, comunicar y confrontar al agresor, de ahí que no se atreva a denunciar.

\section{Manifestaciones culturales}

De acuerdo con las expresiones de los acosadores, el cyberbullying es una suerte de fetiche. Por una parte, el acoso es la marca que se impone a la víctima y que se busca difundir por todos los medios posibles: fotos, videos, mensajes de voz, escritos, etc., pero, por otro lado, la burla, la crueldad y el sometimiento que se ponen en práctica de manera recurrente adoptan la forma de expresiones legítimas que encarnan en sí mismas poder para el acosador. De esta manera, la trama de símbolos que giran alrededor del acoso le confieren un significado especial a los procedimientos violentos que hacen posible su perpetuación. 
Buena parte de las respuestas de los entrevistados coincide en legitimar el cyberbullying, a través de expresiones como una forma de "llevarse en la escuela", "lo normal entre la banda", como parte de una cultura, entendida como tradiciones, valores, costumbres del contexto que comparten ciertos grupos. Willis (1988) señaló al respecto que para los estudiantes catalogados como problemáticos, lo "emocionante" que compartían era quebrar la ley, en donde la violencia era un referente en la construcción de su identidad, una suerte de honor que se valora entre los integrantes del grupo de amigos.

En el discurso de los acosadores se banaliza la violencia, en el sentido de que se trata de un proceso que es parte de la cotidianeidad, y a pesar de tratar de ser impedido por la institución, es para ellos "erigido en norma de conducta, e incluso valor" (Dejours, 2006, p. 114). Por esta razón, las actitudes violentas se tornan comunes y triviales en el contexto escolar; se tienden a minimizar la violencia ejercida por parte de los acosadores para justificar las diversas agresiones que ponen en marcha, por ejemplo, este testimonio:

Alumna, preparatoria pública: "No fue para tanto, fue una broma pesada nomás, pero así nos llevamos". (Ent.11.06.19)

En este sentido, los entrevistados, señalan que no se trata de acciones individuales, y es común que lo comuniquen a un compañero o al círculo próximo de amigos, por lo que acosar a la víctima es parte de su ethos y su comportamiento se integra por completo a esta serie de referentes que se valoran como un logro, que no es otra cosa que la legitimación de un procedimiento violento relacionado con una actitud triunfante:

Alumno, preparatoria pública: "Lo hicimos como reto [...], sí [...] a que hiciera cosas [...], que le escupiera a un güey, que me pasara una feria (dinero) y así, como competencia, estaba chido [...], ino soy el único que lo hace eh!, pero a mí me chingaron". (Ent.07.09.18)

Otro de los argumentos encaminados a justificar el acoso fue llevarlo a cabo como parte de un "pasatiempo":

Alumno, secundaria privada: "Neta que era para pasar el rato, pasatiempo [...], era bien chispa ver cómo se cagaba de miedo el compa ese". (Ent.15.04.19)

La extorsión es otra de las razones que manifiestan, ya sea para adquirir bienes materiales o dinero, incluso los entrevistados señalan que es como una "fuente de ingresos", lo que ha llevado a que algunos autores (Masoomeh et al., 2019; Wagner, 2019) lo tipifiquen como un delito, equiparándolo con la coerción y el robo. El siguiente testimonio es un ejemplo de sextorsion:

Maestra de Biología, secundaria privada: "Eran novios, sí muy discretos [...], pero un grupito de tercero les empezó a pedir dinero que los 100 , que los 500, los mil y así hasta que ya no pudieron pagar $[\ldots]$, y los empezaron a robar $[. .$.$] , que los tenis, que la mochila, el celular [...]$ los amenazaban de que iban a decir en la escuela y a sus papás que eran homosexuales y así los trajeron [...], y cuando los descubrimos ¿qué crees? ininguno estaba arrepentido!, ihasta orgullosos estaban!, y que era isu fuente de financiamiento!, iasí textual!, una pena la juventud de ahora, icomo delincuentes!". (Ent.14.05.19)

En el mismo sentido:

Alumno, preparatoria pública: "que me depositara una lana, eso fue [...] 200 pesos, luego 300, llegó hasta los 800 [...] a una cuenta [...], lo amenacé con putearlo y secuestrarlo [...], pero ya no se pudo [...] (risas)". (Ent.12.07.19) 
En el caso de las mujeres, el cyberbulling está asociado a múltiples alusiones sexuales, relacionadas con su intimidad, hablar de su vida privada sin su consentimiento y difundir fotos de distintas partes de su cuerpo de manera masiva:

Alumno, secundaria privada: "Su prima dice que de chica era bien puta y orita itambién! (risas)". (Ent.41.07.19)

Alumna, preparatoria pública: "Esta es la pinche zorra caliente (se incluye una imagen de la víctima en prendas menores), por si la ves ya sabes lo que le gusta". (Imagen, 23.11.18.

O en franca actitud de extorsión, bajo la amenaza de publicar fotos, videos o información acerca de la intimidad de la víctima:

Alumno, secundaria pública: "Ya cabrona, bájale a tus mamadas voy mandar el video donde te cojo y para que vean tus jefes lo puta que eres". (Mensaje de texto, 15.04.19)

Los diversos testimonios exponen claramente como se "crean y recrean códigos y legalidades subterráneas distintas, que difícilmente logran traducción en el registro educacional adulto" (García y Madriaza, 2006 p. 254). Los acosadores ejercen un control del contexto, a través de mecanismos como la intimidación, la burla y el chantaje que les permiten proteger, conservar y extender sus jerarquías en la institución.

\section{Identidad(es)}

El yo en línea da libertad absoluta en la transformación de identidades, así como la invasión a la vida de otras personas con facilidad. La identidad virtual en el cyberbullying adquiere una importancia central, pues el acosador actúa desde el anonimato, ocultando su identidad y lo hace en función de cuestionar cualquier aspecto de la víctima, con la finalidad de deteriorar su identidad (Goffman, 2006), pues de lo que se trata es de destruirla y llevarla al límite, a través de establecer un estigma permanente, cuyo testigo no es solo el acosador, sino de manera indirecta un número indeterminado de destinatarios al compartir la información en el ciberespacio y con ello ganar prestigio: "Por mi identidad aplasto la tuya" (Restrepo, 2002, p. 75), lo que metafóricamente se denomina la fórmula del vampiro: "Derramo tu sangre para poder sobrevivir" (Restrepo, 2002, p. 75).

Las amenazas y las acciones arbitrarias encuentran en el anonimato un fuerte respaldo en "cómo nos comportamos, virtualmente hablando, no tiene ninguna correspondencia en cómo lo hacemos en nuestra vida cotidiana" (Muros, 2011, p. 52).

Con el internet y la presencia de las redes sociales han aparecido novedosas formas de comunicación por parte de los individuos, en ocasiones, en franca contradicción. Por ejemplo, algunos de los acosadores en este trabajo gozaban de reconocimiento entre pares y se distinguían por apoyar a sus compañeros, todo lo contrario, con los actos de acoso que desarrollaban. La creación de identidades virtuales no permite saber con certeza de quién se trata y de dónde proviene la información que generan, lo que ha modificado los conceptos de tiempo y espacio, en función de la rapidez con que se genera la comunicación: "Digital, hipertextual e hipermedia, de razonamiento rápido, simultáneo, grupal, multipolar, dispersa y circular" (Pérez-Gómez, 2012, p. 16).

La finalidad de estas acciones es crear la sensación de persecución permanente bajo el cobijo del anonimato, en donde no hay límites: es una suerte de violencia limpia (Hirigoyen, 
1999), que no deja huella por parte de quien la ejerce, pero cuyos efectos son devastadores, en cuanto aíslan a la víctima:

Maestra de secundaria pública: "[...] el pobre niño estaba devastado, muy triste, distraído en sus cosas [...], era robustito y no te miento ibajó mucho de peso! [...], icómo en unos días un ser humano puede abandonarse tanto! [...], empezó a no traer tareas, a no participar, hasta que unas niñas me dijeron [...] que lo molestaban en su celular y ¿̇qué crees? resultó ser dizque su mejor amigo (hace comillas con los dedos de su mano derecha en el aire)". (Ent.12.07.19)

La escuela es una arena que se caracteriza por la complejidad inherente que se registra en su seno, así como por la disputa de intereses y proyectos que cada sujeto o grupo en la institución quiere imponer a los demás. En el caso del cyberbullying, los ataques se enfocaban a cuestionar la identidad de la víctima, su "reconocimiento como persona", y excluirlo de la institución, a través de "la violencia relacional porque implica perjudicar o dañar a alguien a través de la difamación, el aislamiento o la manipulación de relaciones (difusión de rumores falsos)" (Bennett et al., 2011, p. 415).

Para la víctima, la pérdida de seguridad que representa la institución está vinculada al anonimato de las amenazas, porque transgreden las normas establecidas, lo que da lugar a sentimientos de impotencia y desamparo, pues "puede ser quien sea el responsable", como comentó un padre de familia. Las entrevistas narran un progresivo cambio de actitud de la víctima: primero, no cree en las amenazas y desestima las acciones; no atribuye al agresor la credibilidad de que lleve a cabo sus acciones:

Alumna, preparatoria pública: "Al principio eran groserías de vez en cuando y luego ya era a cada rato, ya estaba harta". (Ent.11.12.18)

Segundo, la amenaza se convierte en algo real y constante:

Alumna, preparatoria privada: "Lo corté porque era un pinche celoso [...], se volvió loco, mandaba todos los pinches días, fotos de su parte [...], groserías". (Ent.09.05.19)

Finalmente, la víctima, con tal de que el agresor no lleve a cabo su amenaza, obedece y acata las órdenes con la esperanza de que las agresiones disminuyan, sin embargo, ya no hay vuelta atrás, y la violencia se intensifica. En este sentido, el cyberbullying se torna en un mecanismo para la conservación del poder que se apoya en una idealización del agresor, así como por la eficacia de sus métodos, además, genera sufrimiento en el espacio de coexistencia: "Paraliza y deteriora de entrada el espacio psíquico interno propio del sujeto singular, y los espacios comunes y compartidos de los sujetos asociados en las diferentes configuraciones del vínculo" (Kaës et al., 1989, p. 55).

En este proceso de destrucción psíquica de la víctima, el miedo desempeña un papel central. El primer cálculo de que al no denunciar la agresión cesaría fue falso. Los testimonios evidencian que los principales motivos por el que acatan las órdenes son el miedo a ser exhibidas, insultadas, perseguidas y amenazadas por distintas situaciones; lo que es un acto de poder en la medida en que se instrumenta la voluntad de la víctima plenamente, al tiempo que se complementa con la creencia de que el agresor posee un enorme poder, es decir, un acto de dominación basado en los recursos de este y en la posición de emergencia que registra la víctima:

Alumna, preparatoria pública: "Me llegó el mensaje que me cuidara, que anduviera con cuidado porque me iban a secuestrar, desde ese día fue un infierno para mi venir a la escuela". (Ent.24.07.19) 
El cyberbullying ejerce una amenaza permanente que rápidamente se transforma en miedo, el cual lleva a la víctima a modificar sus conductas en el corto plazo y registrar cambios conductuales en su estructura cognitiva con lo que comienzan a respetar de manera inconsciente al agresor, anulando su capacidad de crítica y de cualquier acto de confrontación. Sin embargo, el agresor "no aspira a destruir al otro inmediatamente; prefiere someterlo poco a poco y mantenerlo a disposición. Lo importante es conservar el poder y controlar" (Hirigoyen, 1999, p. 81).

En las víctimas entrevistadas, fue una constante registrar situaciones depresivas: "Me sentí muy triste", "Nadie me hacía caso"; "Te tratan como perro apestado"; "Nadie te quiere hablar o ayudar", "Es la peor cosa de mi vida". Entre otras expresiones, producto de la humillación y agresiones. "Uno de los principales daños es la internalización del miedo crónico que limita de manera importante el desarrollo psicológico y social de la víctima, cerrándole espacios" (Lira y Castillo, 1991, p. 35).

Algunas expresiones de las víctimas son: "¿Cómo le haces?", "¿no sabes qué hacer?", "te paralizas".

Cuando la víctima se somete a la opresión y a las órdenes del acosador, invariablemente se padece un deterioro en su identidad con trastornos psicológicos y sociales graves (Goffman, 2006). Los testimonios muestran efectos negativos en el estado emocional, sin embargo, lo que llama la atención es que, en algunos casos, la víctima trató de justificar la agresión recibida:

Alumna de preparatoria privada, 19 años: "Empezaron a chingar y a mentarme la madre, me bloquearon del face y del Whats nomás [...], porque no quise ir a la bienvenida, creo que tienen razón de molestarse porque si uno va a ser su amiga pues hay que compartir cosas". (Ent.12.03.19)

La presencia del cyberbullying en las escuelas se ha popularizado. En el caso de las víctimas, quienes lo han padecido y conocen sus alcances, se convierte en ocasiones en un referente importante al momento de afrontar un conflicto, pues lo visualizan como un recurso válido, como en dos casos identificados, dando paso a la reproducción de la violencia, como lo muestran los siguientes testimonios:

Alumno de secundaria privada: "A mi me lo hicieron y me chingaron un resto, me agarraron de su pendejo [...], pero yo también dije: ia chinga!, iPor qué a mi nomási y así empecé a puterame a un güey $[\ldots .$.$] , neta que si se siente culero, pero yo no me iba a quedar con mi coraje, ini$ madresi y ni modo, algún compadre tenía que pagar". (Ent.09.07.19)

La víctima relató que mostraron, sin su consentimiento imágenes de contenido sexual, a lo que posteriormente ella respondió con una actitud similar:

Alumna de 15 años, secundaria pública: "[...], pasaron unas fotos mías enseñando las chichis en una fiesta, se pasaron de vergas [...] me puse medio peda y me aloqué y sí [...]. Pero después me desquité, en la foto (enseña la imagen) saqué a un cabrón que se empedó y se quedó sentando en el baño (risas) [...], ia huevo que la publiqué!". (Ent. 21.06.19)

La respuesta de la joven involucrada que ha padecido una socialización violenta conoce los medios e incluso las justificaciones culturales para hacer del cyberbullying un proceso legítimo para afrontar el conflicto, dando lugar a la reproducción de la violencia y nuevas situaciones de acoso. 


\section{Conclusiones}

La producción académica sobre el cyberbullying es amplia y se ha estudiado principalmente a través de estudios de corte cuantitativo, por esta razón, se buscó indagar desde una perspectiva cualitativa, utilizando herramientas etnográficas, con el propósito de recuperar la voz de los sujetos.

A través de las entrevistas, se logró identificar la narrativa expresada por los acosadores, caracterizada por la justificación de los actos de violencia, como parte de una cultura escolar juvenil que desean perpetuar. Por medio de una explicación detallada del ejercicio de las distintas estrategias y recursos utilizados sobre la víctima, los acosadores ejemplificaron sus acciones, sin mostrar arrepentimiento alguno, sino una suerte de exaltación de sus acciones, la promoción de un imaginario violento en torno a la víctima, encaminado a generar desconfianza, inseguridad y miedo. En contraste, y gracias a la observación, se constató en las víctimas la inestabilidad en su estructura psicológica: sentimientos de intranquilidad, angustia, culpa, vergüenza (incapacidad para mirar a los ojos de otras personas, enrojecimiento de rostro, titubeos al hablar, manos sudorosas, largas pausas para relatar lo acontecido) y miedo al asumir con obediencia ante las amenazas recibidas, así como la incapacidad para confrontar las agresiones de que habían sido objeto.

El archivo de acoso que se logró reunir aportó información sobre los recursos de poder. Los videos, mensajes de texto y fotografías recuperados dan cuenta de las amenazas, que se caracterizan por la justificación del ejercicio de la fuerza que dicen poseer, respaldadas con imágenes en donde se muestra la crueldad extrema, por ejemplo, personas mutiladas, secuestradas, torturadas, etcétera, acompañadas de leyendas como: "Eres tú", "esto te va a pasar", "tu futuro"; pero también el control sobre las víctimas, en situaciones relacionadas con la sexovenganza, el sexting o la sextorsion, aunque es importante señalar que este tipo de agresiones tienen como destinatarias a las mujeres principalmente, pero provienen tanto de hombres como de mujeres.

Los mensajes de texto y leyendas, así como los memes coinciden en descalificar, segregar y crear atributos negativos del individuo acosado, es decir, un acto simbólico de distanciamiento de la víctima, en tanto que el cúmulo de imágenes, fotos y videos, representan la promoción y sostenimiento de una cultura de acoso, así como un sentimiento de pertenencia al grupo de victimarios y de los distintos medios de los que puede hacer uso.

Considerando la producción científica revisada, sería conveniente llevar a cabo estudios mixtos, multidisciplinarios, así como de abordajes inter y transdisciplinarios. Otro aspecto importante es que son escasas las investigaciones que, a través de la investigación comparada, a nivel local, nacional, regional e internacional, aporten información para comprender el fenómeno del cyberbullying desde diversos contextos.

En relación con el objetivo general planteado: analizar el fenómeno del cyberbullying en seis escuelas secundarias (con estudiantes de entre 12 y 15 años) y cuatro preparatorias (con estudiantes de entre 16 y 19 años), tanto públicas como privadas del Estado de Colima. De acuerdo con las categorías y subcategorías desarrolladas a lo largo de la investigación, el cyberbullying se define como un problema social que surge como consecuencia de una relación de poder, que se manifiesta a través del constante intento de imponer por la fuerza la voluntad del agresor a otro individuo, en el contexto escolar y con una narrativa que, para ciertos grupos de jóvenes, justifica tanto las acciones como las estrategias violentas, con el propósito de controlar, manipular y deteriorar por distintas vías la identidad de la víctima, utilizando 
dispositivos tecnológicos para ejercer la violencia psicológica y verbal principalmente, y cuyas repercusiones tienen implicaciones en el ámbito escolar, familiar y social.

Por lo que se refiere a los objetivos específicos: a) caracterizar razones y acciones utilizadas por los alumnos considerados acosadores y víctimas, así como decisiones adoptadas y consecuencias de sus conductas, podemos señalar lo siguiente: para los acosadores es una forma de mostrar su poder de manera constante, así como los recursos que posee para controlar a quien él decide - bajo sus criterios-, que debe ser una víctima; manifiesta satisfacción que lo hace sentir victorioso por mantener bajo su dominio a la víctima a quien somete de diversas formas y mecanismos; lo ejerce como un mecanismo de reconocimiento y protección en contra de posibles agresiones: "Es mejor ser acosador que víctima" y es un elemento clave para la construcción del prestigio en el contexto de una cultura escolar para un determinado sector juvenil que se resume en "así nos llevamos", a costa del maltrato y humillación de la víctima. En relación con las víctimas, no denuncian porque han perdido la confianza en que la institución o alguno de sus integrantes, los ayuden; no informan porque, además de sentirse culpables, se avergüenzan de no poder defenderse y evitan la confrontación por el miedo que genera esta situación, pues no se consideran capaces de resolverlo por sus propios medios.

En cuanto a los objetivos específicos: b) conocer la opinión de directivos, docentes, padres de familia y estudiantes sobre el fenómeno del cyberbullying, se anota lo siguiente: para los directores, se trata de un fenómeno complejo para la gestión escolar que va en aumento y que requiere de capacitación al personal docente y de apoyo para poder atenderlo oportunamente; debido a la gravedad de las acciones registradas como amenazas de muerte, secuestros, mutilaciones y extorsiones principalmente, se requiere de asesoría jurídica para orientar al personal de la institución, así como a los involucrados y sus familias.

Los docentes opinan que es difícil prevenir y solucionar este fenómeno, pues no tienen información suficiente y capacitación para intervenir adecuadamente, además que establecer los límites de su responsabilidad resulta complejo, pues algunos hechos suceden fuera de la escuela; demandan apoyo para asistir a cursos, así como recibir orientación legal para saber cómo ayudar a las víctimas, acosadores y a sus padres. De acuerdo con la opinión de los padres que están directamente involucrados en un conflicto de cyberbullying, culpan a la institución y a sus integrantes de no solucionar a tiempo el problema; les cuesta trabajo reconocer el papel que desempeñan sus hijos en el conflicto y se quejan de que la escuela no intervenga oportunamente, así como de que no cuente con la información suficiente para poder orientarlos adecuadamente. Los estudiantes lo reconocen como un problema frecuente en la convivencia cotidiana y que va en aumento, por lo que manifiestan que están expuestos a padecerlo; no le prestan mucha importancia mientras no les afecta directamente, incluso no consideran grave comentar y difundir los mensajes o imágenes de las agresiones, pues, en su opinión, es parte de la cultura escolar.

Sobre el tipo de escuela y género de los involucrados, no hay una diferencia significativa entre las escuelas públicas y privadas: 4 víctimas y 2 acosadores respectivamente, sin embargo, son las mujeres quienes más padecen este tipo de acoso por poco margen, 5 de 8 casos registrados. En la preparatoria pública se registraron más casos de víctimas con 5, que en la escuela particular con 2. Las mujeres fueron quienes más registraron, por poco margen con 4 el número de víctimas, pues los hombres presentaron 3 casos. La incidencia de acoso sexual sobre las mujeres pone de manifiesto la violencia masculina que se práctica en los espacios educativos como una manifestación del abuso de poder y el deseo de control por parte de los agresores. El común denominador en todos los casos es que se trata de un proceso que viola la integridad física, social o psicológica de un individuo. 
Algunas de las limitaciones encontradas para la realización de este trabajo es que cada vez es más complicado ingresar a las escuelas para realizar investigaciones sobre violencia escolar, porque se trata de un tema muy sensible e incómodo para sus integrantes, por lo que requiere de apoyo por parte de las autoridades educativas, así como llevar a cabo múltiples gestiones para la concertación de las entrevistas y lograr la permanencia en la institución.

Es de destacarse que durante el desarrollo de este trabajo se denunciaron varios casos y hechos asociados al cyberbullying en los distintos planteles. No obstante, el plazo establecido para realizar la investigación finalizó y ya no se pudieron considerar para su análisis.

Un reto importante fue la obtención de la evidencia empírica: mensajes de texto, fotografías, imágenes y videos, con la autorización de los padres, docentes, acosadores y víctimas; una serie de documentos y materiales gráficos no fácilmente accesibles, y por lo tanto poco estudiados para el análisis del cyberbullying. A pesar de registrar varias denuncias, no en todos los casos fue posible obtener el material citado, pues los sujetos involucrados no dieron su consentimiento, por lo que no se consideraron en la muestra.

Las implicaciones que tiene el cyberbullying en las instituciones educativas de Colima son de diversa índole, pues se ha convertido en un fenómeno en ascenso, por ello, es urgente promover la difusión de programas y estrategias implementadas con buenos resultados derivados de trabajos de investigación-, para prevenirlo y que involucre a toda la comunidad escolar. La evidencia de los casos encontrados demuestra que el apoyo, a través de la denuncia que hacen quienes están cerca de la víctima (amigos, hermanos, docentes), es clave para poder intervenir y ayudar en su atención. De ahí la importancia de contar con información oportuna y mantener comunicación constante con estudiantes, docentes, autoridades educativas y padres de familia sobre lo que acontece en la institución, con el propósito de brindar atención de manera oportuna, pues como lo han mostrado los testimonios recopilados es que una vez que el acoso fue denunciado públicamente pierde intensidad.

En los casos identificados, si bien la agresión se hace desde el anonimato, quien la promovió siempre contó con un cómplice o pequeño grupo que apoyó. Por esta razón, es importante indagar sobre las motivaciones y el papel que juegan los testigos, ya que el cyberbullying se manifiesta en dos vertientes, primero como un hecho violento en un contexto específico, que se convierte en representación en el espacio social, a través de la difusión y reproducción en los medios masivos.

Las escuelas tienen escasos recursos para ofrecer una orientación suficiente y preventiva para atender el cyberbullying oportunamente, los protocolos en contra de este tipo de violencia son incipientes y no es clara su aplicación ${ }^{2}$. El tratamiento que se le dio en las instituciones visitadas fue la amonestación, llamada de atención, denuncia ante los padres, pero sin garantía de solución. De igual manera, no se registró un seguimiento puntual de las evidencias por parte de la autoridad educativa de los casos registrados, bajo el argumento de que son "pruebas" cuestionables desde el punto de vista legal.

Finalmente, es importante señalar que la comunicación entre los estudiantes mediada por las redes sociales virtuales se ha incrementado notablemente a raíz de la pandemia y las

\footnotetext{
2 Yucatán está a punto de convertirse en la primera entidad en contar con una ley que sancionará el sexting, la sextorsiony la pornovenganza, de acuerdo con la iniciativa promovida en 2017.
} 
condiciones imperantes apuntan que continuará, lo que genera varias interrogantes y nuevos temas de investigación en el corto plazo, por ejemplo, sobre cómo se expresa el cyberbullying entre los jóvenes en el contexto de la contingencia sanitaria $y$, por ende, posterior a ella, derivada de la presencia del virus SARS-Cov.2.

\section{Referencias}

Adorjan, M. y Ricciardelli, R. (2019). Student perspectives towards school responses to cyberrisk and safety: the presumption of the prudent digital citizen. Learning, Media and Technology, (13), 1-13. https://doi.org/10.1080/17439884.2019.1583671

Aftab, P. (2000). The parents guide to protecting your children in cyberspace. McGraw-Hill.

Agnew, R. (2001). Building on the foundation of general strain theory: Specifying the types of strain most likely to lead to crime and delinquency. Journal of Research in Crime and Delinquency, 38(4), 319-361. https://psycnet.apa.org/record/2001-05170-001

Akers, R. (1998). Social Learning and Social Structure: A General Theory of Crime and Deviance. Northeastern University Press.

Al-Rahmi, W., Yahaya, N., Alturki, U., Alrobai, A., Aldraiweesh, A., Alsayed, A. y Bin Kamin, Y. (2020). Social media-based collaborative learning: the effect on learning success with the moderating role of cyberstalking and cyberbullying, Interactive Learning Environments, 28(4), 13-23. https://doi.org/10.1080/10494820.2020.1813180

Arendt, H. (1970). Sobre la violencia. Joaquín Mortiz.

Baeza, C., Vidrio-Patrón, F., Bruno, A. y Godoy-Esquivel, A. (2010). Acoso severo entre iguales (bullying). El enemigo entre amigos. Acta Pediátrica de México, (31), 149-152.

Baldry, A., Blaya, C. y Farrington, D. (Eds.). (2018). International perspectives on cyberbullying. Prevalence, risk factors and interventions. Palgrave Macmillan, Springer International Publishing.

Baldry, A., Farrington, D. y Sorrentino, A. (2016). Cyberbullying in youth: a pattern of disruptive behaviour. Psicología Educativa, 1(22), 19-26. https://www.sciencedirect.com/science/article/pii/S1135755X16000075

Bandura, A. (1987). Teoría del aprendizaje social. Espasa-Calpe.

Barzilay, S. (2017). Bullying victimization and suicide ideation and behavior among adolescents in Europe: a 10-country study. Journal of Adolescent Health, (61), 179186. https://doi.org/10.1016/j.jadohealth.2017.02.002

Bennett, D., Guran, E., Ramos, M. y Margolin, G. (2011). College students' electronic victimization in friendships and dating relationships: anticipated distress and associations with risky behaviors. Violence and Victims, 26(4), pp. 410-429. https://www.ncbi.nlm.nih.gov/pubmed/21882666

Bertely, M. (2000). Conociendo nuestras escuelas. Un acercamiento etnográfico a la cultura escolar. Paidós.

Boyle, M. (2020). Power in the Power Threat Meaning Framework. Journal of Constructivist Psychology. https://doi.org/10.1080/10720537.2020.1773357 
Campbell, M., Whiteford, Ch. y Hooijer, J. (2018). Teachers' and parents' understanding of traditional and cyberbullying. Journal of School Violence, 18(3), 388-402. https://doi.org/10.1080/15388220.2018.1507826

Choon, H., Chan, O., Dennis, S. y Wong, W. (2020). The overlap between cyberbullying perpetration and victimisation: exploring the psychosocial characteristics of Hong Kong adolescents. Asia Pacific Journal of Social Work and Development, 30(1), 1-17. https://doi.org/10.1080/02185385.2020.1761436

Coelho, V. y Sousa, V. (2018). Bullying and Cyberbullying Behaviors Questionnaire: Validation of a Short Form. International Journal of School y Educational Psychology, 8(1), 3-10. https://doi.org/10.1080/21683603.2018.1522282

Cohen, L. y Felson, M. (1979). Social Change and Crime Rate Trends: A Routine Activity Approach. American Sociological Review, 44(4), 588-608. http://citeseerx.ist.psu.edu/viewdoc/summary?doi=10.1.1.476.3696

Cortés-Pascual, A., Cano-Escorianza, J., Elboj-Saso, C. e Iñiguez-Berrozpe, T. (2020). Positive relationships for the prevention of bullying and cyberbullying: a study in Aragón (Spain). International Journal of Adolescence and Youth, 25(1), 182-199. https://doi.org/10.1080/02673843.2019.1602064

Dejours, Ch. (2006). La banalización de la injusticia social. Topia Editorial.

Delumeau, J. (2012). El miedo en occidente. Taurus.

Domínguez-Alonso, J., Vázquez-Varela, E. y Nuñez-Lois, S. (2017). Cyberbullying escolar: incidencia del teléfono móvil e internet en adolescentes. relieve, 23(2), 1-11. http://doi.org/10.7203/relieve.23.2.8485

Donoso-Vázquez, T., Rubio, M. y Vilà, R. (2017). Las ciberagresiones en función del género. Revista de Investigación Educativa, 35(1), 197-214. http://dx.doi.org/10.6018/rie.35.1.249771

Escobar, M. (1988). Contribución al estudio del poder. unam-enep-Acatlán.

Espelague, D., Valido, A. y Hong, J. (2018). Cyberbullying in the United States. En A. Baldry, C. Blaya y D. Farrington (eds.), International perspectives on cyberbullying. Prevalence, Risk factors and interventions (pp. 65-100). Palgrave Macmillan.

Foucault, M. (1988). Vigilar y castigar. Nacimiento de la prisión. Sigo XXI Editores.

García, M. y Madriaza, P. (2006). Estudio cualitativo de los determinantes de la violencia escolar en Chile. Estudios de Psicología, 11(3), 247-256. http://www.redalyc.org/pdf/261/26111301.pdf

Geertz, C. (2006). La interpretación de las culturas. Gedisa.

Goffman, E. (2006). Estigma. La identidad deteriorada. Amorrortu Editores.

Gómez-Nashiki, A. (2020, 17 de junio). Cyberbullying, problemas de la gestión de la violencia entre pares en la pandemia. Notas de docentes de educación básica [blog]. Abran su cuaderno, Consejo Mexicano de Investigación Educativa. https://www.comie.org.mx/v5/sitio/2020/06/17/cyberbullying-problemas-en-lagestion-de-la-violencia-entre-pares-durante-la-pandemia-notas-de-docentes-deeducacion-basica/ 
Graham, R. y Wood Jr., F. (2017). Associations between cyberbullying victimization and deviant health risk behaviors. The Social Science Journal, 56(2), 183-188. doi: https://doi.org/10.1016/j.soscij.2018.05.005

Hamal, M., Neupane, S. y Rimpela, A. (2019). Risk factors of cyberbullying and its association with perceived health among finnish adolescents. Vulnerable Children and Youth, Studies, 15(1), 1-12. https://doi.org/10.1080/17450128.2019.1653505

Hammersley, M. y Atkinson, P. (1994). Etnografía. Métodos de investigación. Paidós.

Herrera-López, M., Casas, J., Romera, E., Ortega-Ruiz, R. y Del Rey, R. (2017). Validation of the European Cyberbullying Intervention Project Questionnaire for Colombian Adolescents. Cyberpsychology, Behavior, and Social Networking, 20(2), 117-125. https://doi.org/10.1089/cyber.2016.0414

Herrera-López, M., Romera, E. y Ortega-Ruiz, R. (2018). Bullying y ciberbullying en Latinoamérica. Un estudio bibliométrico. Revista Mexicana de Investigación Educativa, 23(7), 125-155.

Hinduja, S. y Patchin, J. (2018). Connecting adolescent suicide to the severity of bullying and cyberbullying. Journal of School Violence, 18(3), 333-346. https://doi.org/10.1080/15388220.2018.1492417

Hirigoyen, M. (1999). El acoso moral. El maltrato psicológico en la vida cotidiana. Paidós.

Kaës, R., Bleger. J., Enriquez, E., Fornari, F., Fustier, P., Roussillon, R. y Vidal, J. (1989). La institución y las instituciones. Estudios psicoanalíticos. Paidós.

Lehman, B. (2020). Hate at school: victimization and disorder associated with school $\begin{array}{lll}\text { avoidance. Sociological } & \text { Spectrum, }\end{array}$ https://doi.org/10.1080/02732173.2020.1734890

Lira, E. y Castillo, M. (1991). Psicología de la amenaza política y del miedo. Instituto Latinoamericano de Salud Mental y Derechos Humanos, Universidad de Texas.

Masoomeh, S., Shadmanfaat, C., Howell, J., Muniz, C., Cochran, J., Kabiri, S. y Fontaine, E. (2019). Cyberbullying perpetration: an empirical test of social learning theory in Iran. Deviant Behavior, 41(3), 278-293. https://doi.org/10.1080/01639625.2019.1565513

Menge, T. (2019). Violence and the materiality of power. Critical Review of International Social and Political Philosophy. https://doi.org/10.1080/13698230.2019.1700344

Miles, B. y Huberman, A. (1994). Qualitative data analysis: a source book of new methods. Sage.

Miller, K. (2017). Cyberbullying and its consequences: how cyberbullying is contorting the minds of victims and bullies alike and the law's limited available redress. Southern California Interdisciplinary Law Journal, 26, 379-404. https://gould.usc.edu/why/students/orgs/ilj/assets/docs/26-2-Miller.pdf

Muros, B. (2011). El concepto de identidad en el mundo virtual: el yo online. Revista Electrónica Interuniversitaria de Formación del Profesorado, 14(2), 49-56. http://www.redalyc.org/articulo.oa?id=217019031004

Olweus, D. (2003). Conductas de acoso y amenaza entre escolares. Morata.

Paez, G. (2018). Cyberbullying Among Adolescents: A general strain theory perspective. Journal of School Violence, 17(1), 74-85. 10.1080/15388220.2016.1220317 
Pérez-Gómez, Á. (2012). Educarse en la era digital. Morata.

Priya, S., y Eshan, B. (2019). Online peer victimization. Journal of Information Technology Case and Application Research, 21(3-4), 115-123. https://doi.org/10.1080/15228053.2019.1667665

Purdy, N. (2019). Bullying, cyberbullying and student well-being in schools: comparing European, Australian and Indian perspectives, Pastoral Care in Education, 37(4), 347348. https://doi.org/10.1080/02643944.2019.1661172

Redondo-Pacheco, J., Luzardo-Briceño, M., Inglés-Saura, C., y Rivas, E. (2018). Ciberacoso en una muestra de adolescentes de instituciones educativas de Bucaramanga. Psychologia, 12(1), 35-44. https://doi.org/10.21500/19002386.3366

Restrepo, L. (2002). Más allá del terror. Abordaje cultural de la violencia en Colombia. Aguilar.

Ricoeur, P. (2007). Tiempo y narración I. Configuración del tiempo en el relato histórico. Siglo XXI Editores.

Rodríguez, A. (2002). Una lectura psicosocial del miedo: la experiencia argentina reciente. Revista de Psicología Social, 17(1), 85-101.

Rosa, I., Nacimiento, L., y Mora-Merchán, J. (2018). Procesos metacognitivos en la selección de conductas que emiten los universitarios en bullying y cyberbullying. Informes Psicológicos, 18(1), 35-52. http://dx.doi.org/10.18566/infpsic.v18n1a02

Scheerder, A., Van Deursen, A. y Van Dijk, J. (2019). Negative outcomes of Internet use: A qualitative analysis in the homes of families with different educational backgrounds. The Information Society, 35(5), 286-298. https://doi.org/10.1080/01972243.2019.1649774

Seetharaman, P. y Bhatt, S. (2019). Online peer victimization. Journal of Information Technology Case and Application Research, 21(3-4), 115-123. https://doi.org/10.1080/15228053.2019.1667665

Shiakou, M. y Piki, L. (2018). Assessing the role of drama on children's understanding of bullying. International Journal of School y Educational Psychology, 8(1), 11-20. https://doi.org/10.1080/21683603.2018.1499574

Slattery, L., Peshak, H. y Kern, L. (2019). Defining the word bullying: inconsistencies and lack of clarity among current definitions, Preventing School Failure: Alternative Education for Children and Youth, 63(3), 227-235. https://doi.org/10.1080/1045988X.2019.1579164

Smith, P., Mahdavi, J., Carvalho, M., Fisher, S., Russell, S. y Tippett, N. (2008). Cyberbullying: Its nature and impact in secondary school pupils. Journal of Child Psychology and Psychiatry, (49), 376-385. https://doi.org/10.1111/j.1469-7610.2007.01846.x

Torres, Ch., D'Alessio, S. y Stolzenberg, L. (2019). The effect of social, verbal, physical, and cyberbullying victimization on academic performance. Victims and Offenders, 15(1), 121. https://doi.org/10.1080/15564886.2019.1681571

Tosuntaş, S., Balta, S., Emirtekin, E., Kircaburun, K. y Griffiths, M. (2018). Adolescents' eveningness chronotype and cyberbullying perpetration: the mediating role of depression-related aggression and anxiety-related aggression, Biological Rhythm Research, 51(1), 40-50. https://doi.org/10.1080/09291016.2018.1513132 
Türker, P. y Çakmak, E. (2019). An investigation of cyber wellness awareness: Turkey secondary school. Students, Teachers, and Parents, Computers in the Schools, 36(4), 293-318. https://doi.org/10.1080/07380569.2019.1677433

Völlink, T., Dehue, F. y Guckun, C. Mc., (2017). Cyberbullying. From theory to intervention. Routlege.

Wagner, A. (2019). E-victimization and e-predation theory as the dominant aggressive communication: the case of cyber bullying. Social Semiotics, 29(3), 303-318. https://doi.org/10.1080/10350330.2019.1587832

Warwick, D. y Purdy, N. (2019). Cartoons as visual representations of the development of primary school children's understanding of bullying behaviours. Pastoral Care in Education, 37(3), 257-275. https://doi.org/10.1080/02643944.2019.1625430

Waters, S., Russell, W. y Hensley, M. (2020). Cyber bullying, social media, and character education: why it matters for middle school social studies. The Clearing House: $A$ Journal of Educational Strategies, Issues and Ideas, 93(3), 1-10. https://doi.org/10.1080/00098655.2020.1760770

Weber, M. (1992). Economía y sociedad. Esbozo de sociología comprensiva. FCE.

Wikström, P. (2014). Why Crime Happens: A Situational Action Theory. Pp. 74-94 in Analytical Sociology: Actions and Networks (G. Manzo, ed.). John Wiley \& Sons Ltd.

Willis, P. (1988). Aprendiendo a trabajar. Cómo los chicos de la clase obrera consiguen trabajos de la clase obrera. Akal.

Yudes-Gómez, C., Baridon-Chauvie, D., y González-Cabrera, J., (2018). Ciberacoso y uso problemático de Internet en Colombia, Uruguay y España: un estudio transcultural. Revista Científica de Comunicación y Educación, 56(3), 1-12. https://doi.org/10.3916/C56-2018-05

Zhen, L. y Yuanyuan, A. (2019). Machiavellianism, Mindfulness and Cyberbullying among chinese junior high school students: the mediating role of empathy. Journal of Aggression, Maltreatment \& Trauma, 29(5), 1-12. https://doi.org/10.1080/10926771.2019.1667467 